\title{
The Rod Pathway in the Rabbit Retina: A Depolarizing Bipolar and Amacrine Cell
}

\author{
Ramon F. Dacheux and Elio Raviola \\ Department of Anatomy and Cellular Biology, Harvard Medical School, Boston, Massachusetts 02115
}

Anatomical and electrophysiological techniques were combined to study the morphology, synaptic connections, and response properties of two neurons in the rod pathway of the rabbit retina: the rod bipolar cell and the narrow-field, bistratified (NFB) amacrine cell. Rod bipolars receive synaptic input from rod cells in the outer plexiform layer (OPL), where their dendrites end as central elements in the invaginating synapse of rod spherules. Their main synaptic output in the inner plexiform layer (IPL) is onto NFB amacrine cells and at least one other type of amacrine, which in turn feeds a reciprocal synapse back onto the bipolar endings. Rod bipolars, or a variety of them, respond to diffuse, white light stimulation with a transient-sustained depolarization dominated by rods; with high-intensity flashes, they generate a secondary depolarization at off, which is homologous to the rod aftereffect of horizontal cells, although opposite in polarity.

NFB amacrine cells receive synaptic input from rod bipolars, cone bipolars, and other types of amacrine cells; they are presynaptic to ganglion cell dendrites and communicate via gap junctions with other processes, whose parent neuron has not yet been identified. They respond to light with a triphasic potential, characterized by a depolarizing transient at on, followed by a sustained plateau phase, and finally by a hyperpolarizing transient at off. Threshold of their responses is the same as in the depolarizing rod bipolars and saturation is reached with nearly the same stimulus intensity in both neurons. Furthermore, NFB amacrine cells exhibit a depolarizing rod aftereffect at the termination of high-intensity flashes. Thus, this amacrine cell type is inserted in series along the rod pathway in the rabbit retina and modulates the transfer of scotopic signals from rod bipolars to ganglion cells.

Our knowledge of the neural networks that process rod signals in the mammalian retina was primarily based on anatomical studies in which the various cell types were identified with the Golgi impregnation technique and their connections analyzed by EM (Boycott and Dowling, 1969; Boycott and Kolb, 1973; Cajal, 1892; Dowling and Boycott, 1966; Kolb, 1970, 1974, 1977, 1979; Missotten, 1965; Polyak, 1941; Raviola and Raviola, 1967). To date, only in the cat has an attempt been made to correlate the morphology and connectivity of the cells with their intracellularly recorded light responses. In the outer plexiform layer (OPL) of this retina, the signals of rod photoreceptors are transmitted to the axonal endings of one type of horizontal

Received Feb. 19, 1985; revised June 3, 1985; accepted July 2, 1985.

We wish to thank Ms. Suzanne Kuffler and Mr. David Sepe for expert technical assistance and Mr. Peter Ley for help with the photography. This work was supported by United States Public Health Service Grants EY 03011 and EY 01344.

Address correspondence to Dr. Ramon Dacheux at the Department of Anatomy and Cellular Biology, Harvard Medical School, 25 Shattuck Street, Boston, MA 02115.

Copyright $(1986$ Society for Neuroscience $0270-6474 / 86 / 020331-15 \$ 02.00 / 0$ cell and to the dendrites of rod bipolars (Nelson, 1977; Nelson et al., 1975, 1976). The axonal endings of rod bipolars synapse in the inner plexiform layer (IPL) with at least five types of amacrine cells, four of which are in turn presynaptic to ganglion cells (Kolb and Nelson, 1981, 1983). Only exceptionally do rod bipolars contact ganglion cell dendrites: Thus, the bulk of the scotopic information is elaborated by amacrine cells. Surprisingly, rod bipolars appear to be hyperpolarizing, whereas the two types of amacrine cells that receive exclusive or predominant input from them are depolarizing. The remaining three types of amacrine cells are all hyperpolarizing, but they receive a predominant cone input (Kolb and Nelson, 1983; Nelson and Kolb, 1983). The rod pathway in the cat has another peculiar feature: The response of the narrow-field, bistratified (NFB) amacrine cell, which represents the main link between rod bipolars and ganglion cells (Famiglietti and Kolb, 1975), is not only reversed in polarity but is also faster than the rod bipolar response. It was thus suggested that a function of this amacrine cell type is to quicken the sluggish signal of the bipolar (Kolb and Nelson, 1983; Nelson, 1982; Nelson et al., 1976).

We report the morphology, connections, and response properties of rod bipolars and NFB amacrine cells in the retina of the rabbit.

\section{Materials and Methods}

Male and female New Zealand albino rabbits were used. The morphology and synaptic connections of rod bipolar and NFB amacrine cells were studied both with the chromo-argentic technique and after intracellular injection of HRP. For silver staining, the rapid Golgi method was used according to the protocol of Morest and Morest (1966) after fixation with $2.5 \%$ glutaraldehyde in $0.1 \mathrm{M}$ Sörenson phosphate buffer. The cells illustrated in Figures 1 and $10 a$ were drawn at the camera lucida from radial sections of the retina and the number of dendritic branchlets in four additional rod bipolars were counted in a flat-mounted specimen. The synaptic connections of a rod bipolar were analyzed with the EM after Golgi impregnation, gold-toning (Dacheux, 1982; Fairén et al., 1977), and thin-sectioning. Intracellular recordings and staining with HRP were carried out in a superfused eyecup preparation, whose details were reported in a previous paper (Dacheux and Raviola, 1982). In brief, the everted rabbit eyecup was exposed to a mammalian bicarbonate Ringer's solution, $\mathrm{pH} 7.4( \pm 0.05)$ at $35^{\circ} \mathrm{C}$, flowing at a rate of $20 \mathrm{ml} / \mathrm{min}$. Diffuse, white light stimuli were focused on the retina from a tungsten/halogen lamp; maximal irradiance $(0.0$ $\log$ units) was $3.78 \mathrm{~W} / \mathrm{m}^{2}$, measured by a Tektronix I 16 irradiance probe. Micropipettes were filled with $4 \% \mathrm{HRP}$ in $0.2 \mathrm{M}$ potassium acetate, and the enzyme was ejected with a positive current of 1 to $2 \mathrm{nA}$ delivered in square pulses of $30 \mathrm{msec}$ duration at a frequency of $15 \mathrm{~Hz}$ for $1-3$ min. The retina was subsequently fixed in aldehydes, processed for the histochemical demonstration of HRP activity, postfixed in osmium tetroxide, stained en bloc with uranyl acetate, and embedded in EponAraldite. Serial thin sections of the stained cells were examined with a Jeol 100-B EM.

Two rod bipolars were successfully injected intracellularly with HRP; since at that time we had not yet developed a technique for simultaneous visualization of the stained neurons with both the LM and EM, the cells were identified at the LM in a hand-cut, radial section of the retina; 

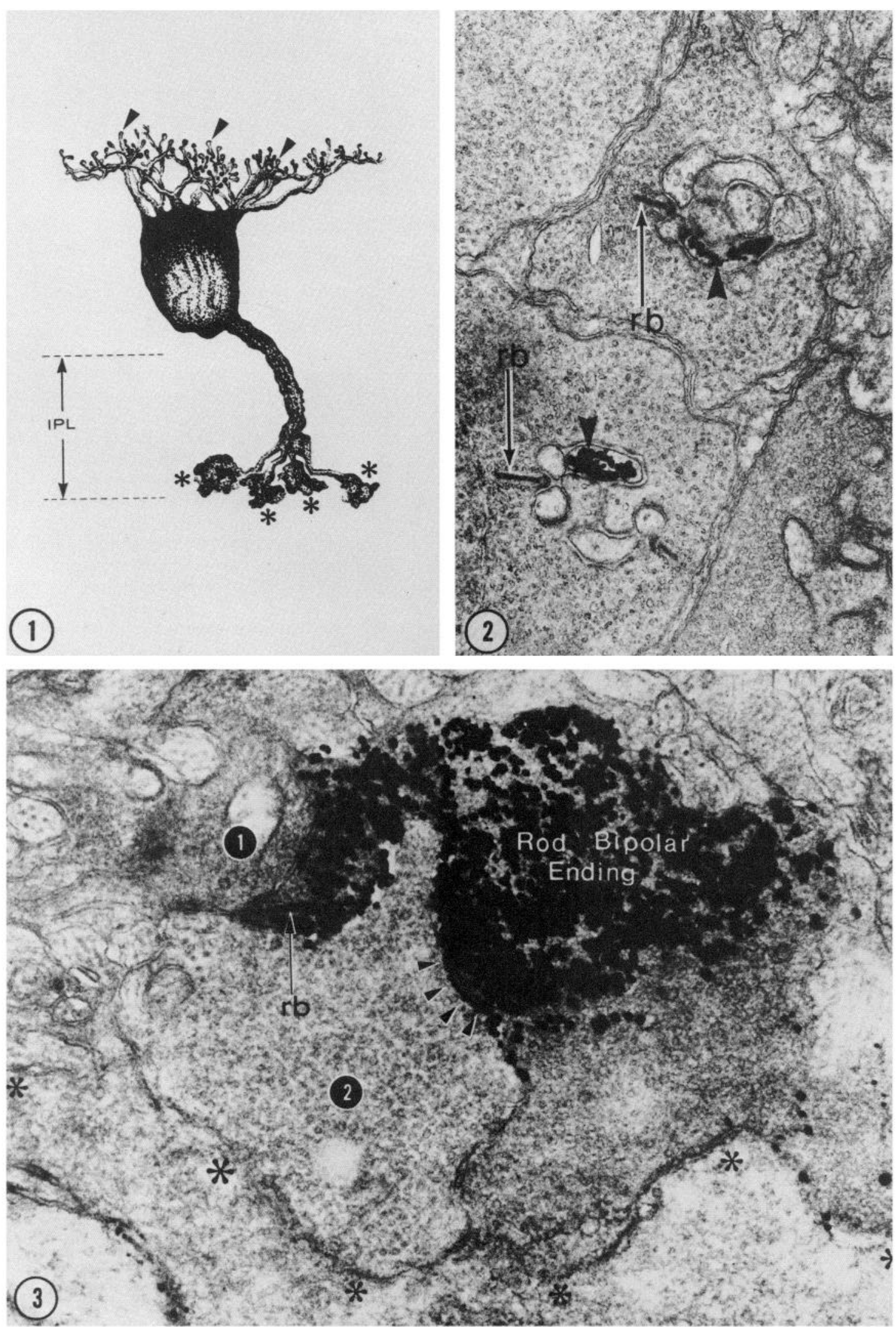

Figures 1, 2, and 3: Figure 1, Rod bipolar cell in the periphery of the rabbit retina, impregnated with Golgi's chromo-argentic technique. The dendrites give rise to a multitude of terminal branchlets (arrowheads), which end with a tiny swelling at the level of the rod spherules in the OPL. The axon is characterized by a small number of large, irregular terminals (asterisks), which are situated at the vitreal boundary of the IPL. Camera lucida drawing. Magnification, $\times 1900$. Figure 2, Golgi-impregnated rod bipolar cell was gold-toned and examined with the EM. Its dendritic branchlets (arrowheads) end in the synaptic invagination of rod spherules. rb, Synaptic ribbons. Magnification, $\times 26,000$. Figure 3, One of the 
thus, light micrographs or camera lucida drawings could not be made. One of the cells was partially masked by the staining of an adjoining Müller cell and was discarded; the other was embedded in plastic, thinsectioned, and examined with the EM.

Eleven NFB amacrine cells were injected with HRP. The retinas containing the stained cells were subsequently flat-embedded in a thin plastic wafer on a glass slide, with the photoreceptors oriented toward the free surface. The intensely osmicated photoreceptor layer and the underlying outer nuclear layer were removed with a precision milling machine to increase the transparency of the retina, and the stained neurons were identified at the LM. In Figures $10, b$ and $c$, two optical sections of an HRP-stained, NFB amacrine cell viewed en face were drawn at the camcra lucida; the ccll was then reconstructed by computer graphics, and its image was rotated to visualize its "profile" view. Finally, this and another NFB amacrine cell were serially thin-sectioned and examined with the EM.

\section{Results}

\section{Rod bipolar cells}

In the rabbit retina, we experienced great difficulty in penetrating rod bipolars with electrodes that can deliver HRP; furthermore, with such electrodes we could not hold the impaled cells long enough to carry out an exhaustive physiological analysis. Thus, we first studied their morphology in Golgi-impregnated retinas at the LM and then utilized the gold-toned, Golgi-impregnated cells to examine their connectivity with the EM. Subsequently, we defined a class of rod-dominated intracellular responses to white light stimulation ( 24 responses): They were obtained at the depth in the retina where the perikarya of rod bipolars are approximately located and had homogeneous waveform, threshold, and saturation properties. In two instances, rod bipolars were positively identified as the source of these responses by intracellular staining with HRP and one cell was examined with the EM.

\section{Light microscopy}

In Golgi-impregnated rabbit retinas, rod bipolars were easily recognized from cone bipolars because of their characteristic morphological features (Fig. 1): Their perikaryon was situated in the scleral region of the inner nuclear layer and gave rise to a dense tuft of short dendrites, which were studded with a multitude of terminal branchlets. These followed a vertical course and terminated with a tiny swelling at the level of the array of rod spherules in the scleral tier of the OPL. The number of the terminal branchlets varied greatly among different rod bipolars, even in the same retinal region: Some 80-120 branchlets were counted in four cells, which were located midway between optic nerve head and retinal periphery. The axon of the rod bipolars terminated with a small number of short branches, which expanded into large, irregular synaptic endings, up to $3.5 \mu \mathrm{m}$ in size, situated at the extreme vitreal boundary of the IPL.

\section{Electron microscopy}

Examination with the EM of a Golgi-impregnated, gold-toned rod bipolar showed that the terminal branchlets of its dendritic tree penetrated the synaptic invagination of rod spherules (Fig. 2).

At the vitreal border of the IPL its axonal endings made ribbon synapses with two postsynaptic processes (dyad synapse, Fig. 3): One had large diameter and pale matrix, contained numerous synaptic vesicles and returned a conventional, reciprocal synapse onto the bipolar ending. The other had small diameter, denser matrix, and in places contained a heterogeneous population of tubules, vacuoles, and multivesicular bodies. In addition, this process did not appear to establish a feedback synapse onto the bipolar ending. In the sections examined, the axon terminal of this rod bipolar did not contact ganglion cell dendrites. However, bipolar-to-ganglion cell synapses may have escaped our attention, for we did not attempt a threedimensional reconstruction of the synaptic connections of the endings.

Examination of the HRP-stained rod bipolar proved that the vast majority of its dendritic branchlets occupied a central position in the invaginating synapse of rod spherules (Figs. 4 and 5); their summits were shielded from the presynaptic ridge by the apposing surfaces of the deeply recessed lateral elements, which represent telodendria of axonal endings of axon-bearing horizontal cells (Dacheux and Raviola, 1982). However, among the multitude of dendritic branchlets of this cell, two ended in a synaptic invagination of two cone pedicles; one of these branchlets could be followed to its termination and was seen to occupy the central position in the triad of postsynaptic processes. The axonal endings of this bipolar cell were located at the vitreal boundary of the IPL and established dyad synapses with pairs of postsynaptic processes, thus conforming to a pattern typical for all rod bipolars (Fig. 6).

\section{Electrophysiology}

Intracellular responses from rod bipolars consisted of graded, biphasic depolarizations to step changes in the intensity of diffuse, white light stimuli (Fig. 7) and were strongly reminiscent of the bipolar cell responses in the mudpuppy (Werblin and Dowling, 1969), goldfish (Kaneko, 1970), and rabbit (Dacheux and Miller, 1981). The cells began to respond with slow, monophasic depolarizations to a stimulus intensity of $-6.0 \mathrm{log}$ units or one log unit below threshold for the electroretinogram b-wave. As the stimulus intensity increased, the waveform of the response became biphasic: A transient component appeared at stimulus initiation, followed by repolarization to a sustained plateau phase, which promptly returned to dark level at the termination of the illuminating flash. The amplitude of the transient increased almost linearly throughout the range of the lowintensity stimuli and reached saturation with flashes two $\log$ units above threshold $(-4.0)$. With intermediate intensities, or one $\log$ unit above saturation $(-3.0)$, the sustained plateau phase began to slowly decay at off, instead of promptly returning to dark level. With brighter stimuli $(-2.0$ to 0.0$)$, a secondary, depolarizing aftereffect appeared at off, which was equal to or larger in amplitude than the sustained plateau phase of the primary response and slowly returned to dark level with a time course of several seconds. A similar, slow afterpotential, although opposite in polarity, was observed in the responses to high-intensity light of the axon terminal of axon-bearing horizontal cells, which is also postsynaptic to rods (Dacheux and Raviola, 1982).

Figure 8 illustrates the effect of dark and light adaptation on the waveform and amplitude of the response of a rod bipolar. The responses in the left-hand column were obtained from a dark-adapted retina. When a continuous background light of $-5.0 \log$ units was delivered to the retina (center column), threshold increased $1.5 \log$ units (from -6.0 to -4.5 ) and the response became attenuated without losing its biphasic waveform. Saturation was again reached at $-4.0 \mathrm{log}$ units, and the

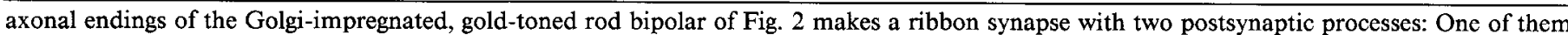

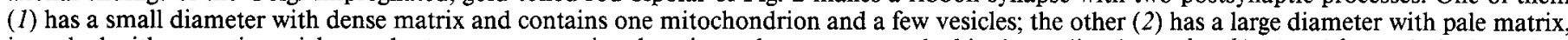

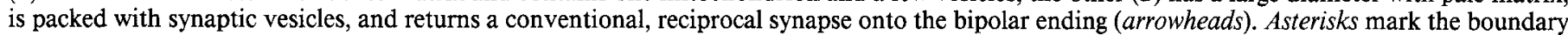
between IPL and ganglion cell layer. $r b$, Synaptic ribbon. Magnification, $\times 52,000$. 

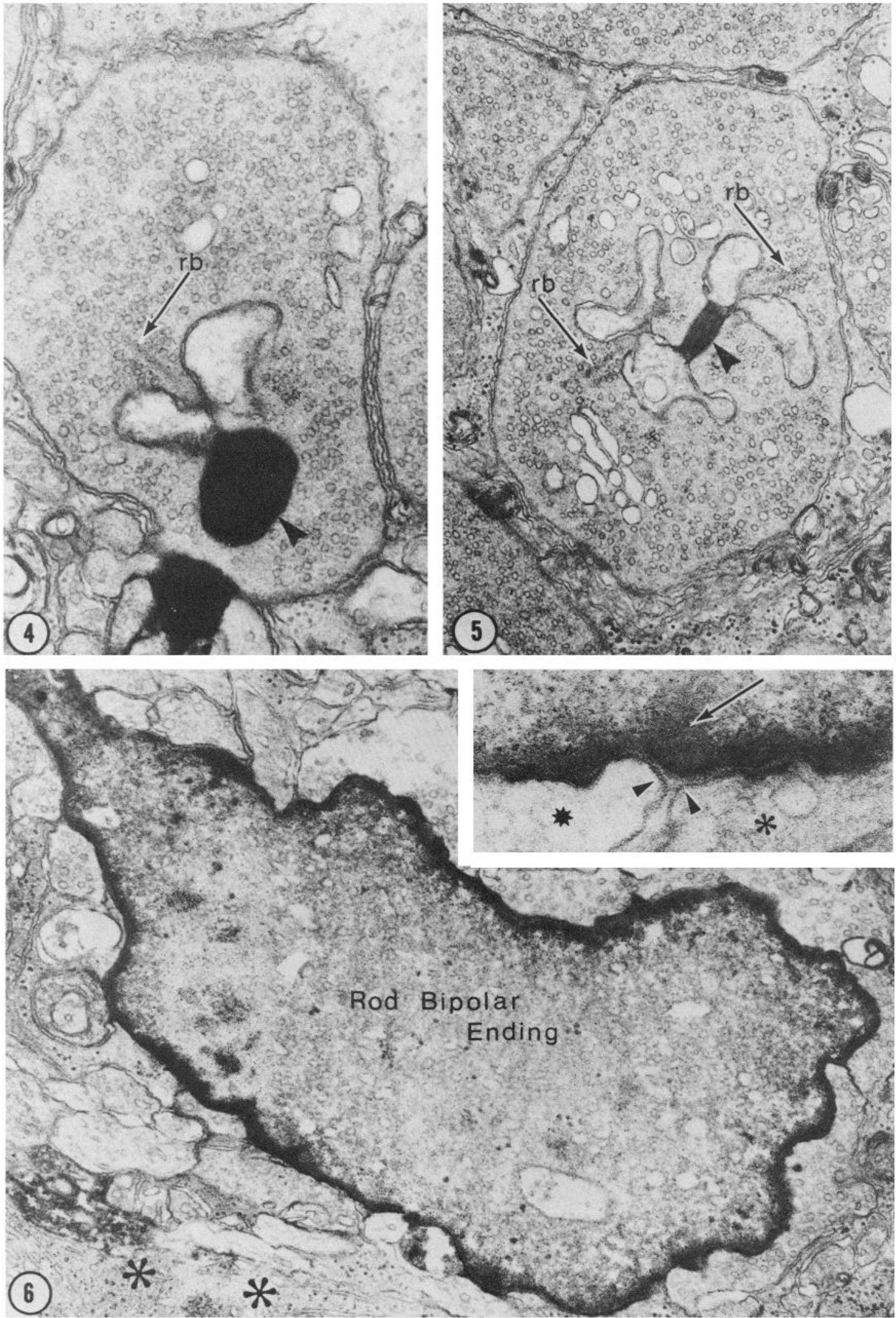

Figures 4, 5, and 6: Figures 4 and 5, The cell whose light responses are illustrated in Fig. 7 was injected with HRP and examined with the EM. The vast majority of its dendritic branchlets (arrowheads) occupy a central position in the synaptic invagination of rod spherules. $r b$, Synaptic ribbons. Magnification, $\times 41,000$ (Fig. 4) and $\times 40,000$ (Fig. 5). Figure 6, Axon of the HRP-injected rod bipolar of Figures 4 and 5 gives rise to large terminals situated at the vitreal boundary of the IPL (asterisks). The endings make dyad synapses with pairs of postsynaptic processes (inset). In each pair, one process has a dense matrix and few vesicles (asterisk), the other has pale matrix and numerous synaptic vesicles (star). The presynaptic ribbon (arrow) is masked by the dense product of the histochemical reaction for HRP. Magnification, $\times 43,000 ;$ inset, $\times 86,000$. 
depolarizing aftereffect was retained with high stimulus intensities. When the background illumination was increased to a saturating intensity ( $-4.0 \mathrm{log}$ units; right-hand column), test stimuli of any brightness failed to evoke a response from the bipolar cell. Clearly, a background illumination of $-4.0 \mathrm{log}$ units saturates the rods, which represent the major source of synaptic input into this bipolar type. This conclusion is further substantiated by the fact that adaptation with this background light abolishes the rod aftereffect in axonless horizontal cells.

To test the spatial properties of the response of the rod bipolar cells, the diameter of the stimulus centered over the tip of the electrode was varied, whereas its intensity was kept constant at $-3.0 \log$ units. Little or no change was observed in both waveform and amplitude of the response as the size of the illuminating spot was decreased to $400 \mu \mathrm{m}$. With a $300 \mu \mathrm{m}$ stimulus, the amplitude of the response decreased and the on-transient became less prominent (Fig. 9). A $100 \mu \mathrm{m}$ spot produced a lowamplitude, monophasic potential, similar to the center response of other vertebrate bipolar cells. Unfortunately, the cells were never held long enough to position over the electrode an annulus of appropriate size or to displace the illuminating spot toward the periphery of the cell's receptive field; thus, the cells could not be tested for a pure surround response.

\section{Narrow-field bistratified (NFB) amacrine cells}

NFB amacrine cells are very small neurons, and yet they were surprisingly easy to penetrate with microelectrodes and stain with HRP. Thus, the source of all intracellular responses (11) described in this section was anatomically identified.

\section{Light microscopy}

NFB amacrine cells had a round cell body, 5-10 $\mu \mathrm{m}$ in diameter, located in the vitreal region of the inner nuclear layer, at the very border of the IPL (Fig. 10). Typically, a thick primary dendrite emerged from the perikaryon and descended toward the vitreal region of the IPL, where it expanded into a conical tuft of secondary branches. Thin, collateral processes arose from the scleral aspect of the body, from the primary dendrite, and occasionally from the initial portion of its secondary branches; these ran a tortuous, tangential course in the scleral region of the IPL and carried endings, both terminal and en passant. The endings were irregular in shape and sizc, but they typically appeared very large, reaching $2-3 \mu \mathrm{m}$ in diameter; they were named lobular appendages in the cat retina (Famiglietti and Kolb, 1975). The secondary branches of the main dendrite further subdivided as they traversed the vitreal region of the IPL and, finally, they spread tangentially at the boundary between the IPL and ganglion cell layer. Along their course they gave rise to occasional spiny projections and toward their end, they carried irregular swellings up to $1.5 \mu \mathrm{m}$ in diameter. This amacrine cell was therefore distinctly bistratified, for it sent processes of remarkably different morphology to the scleral and vitreal regions of the IPL. The dendritic field of NFB amacrine cells was roughly circular, with a diameter ranging between 30 and $50 \mu \mathrm{m}$ in the midperiphery of the retina; in general, the spread of the lobular appendages was smaller than that of the vitreal arborization (Fig. 10,b-d).

\section{Electron microscopy}

The analysis of the connectivity of NFB amacrine cells was limited to the examination of two HRP-stained cells. As the dense HRP reaction product obscured the cytoplasmic details of the presynaptic active zone, it was difficult to identify the cells' synaptic outputs; this was especially true for the lobular appendages, in which vesicles were packed throughout the ending, rather than forming discrete clusters at the presynaptic active zones. For this reason, the connectivity of NFB amacrine cells reported in this paper is by necessity incomplete. A three-
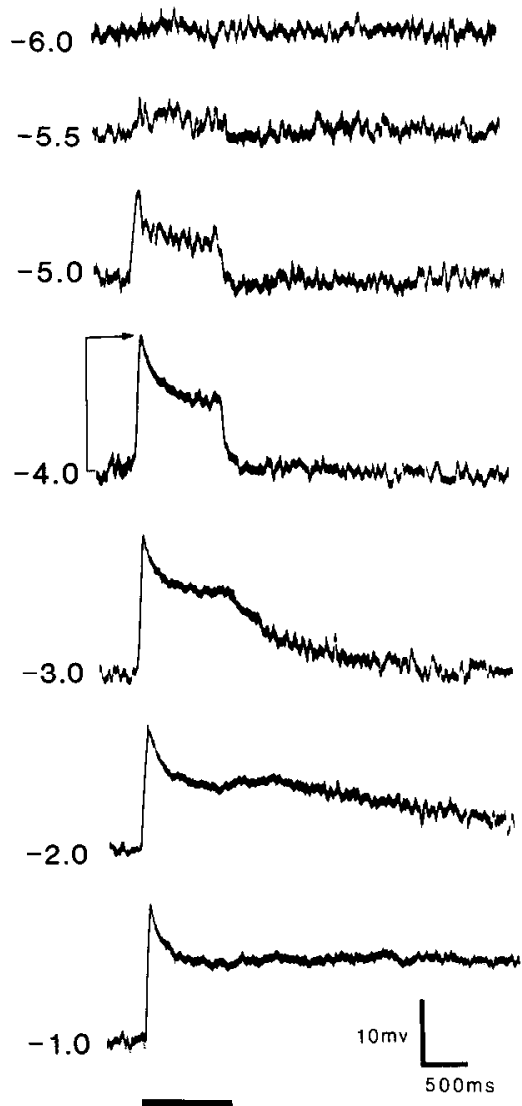

Figure 7. Depolarizing reponses to diffuse, white light stimulation of a retinal neuron that was subsequently identified as a rod bipolar by HKP-injection (Figs. 4-6). Threshold responses were obtained with a stimulus intensity of $-6.0 \mathrm{log}$ units. With $\mathrm{a}-5.0$ flash, a transient component appeared at the onset of illumination, followed by a sustained plateau phase, which promptly returned to dark level at off. The response reached saturation at an intensity of $-4.0 \log$ units. With brighter stimuli $(-3.0$ to -1.0$)$, the cell developed a slow depolarization at off, which returned to baseline with a time course of several seconds. The amplitude measurements reported in the text were made at the point indicated by the arrow. The presentation of the stimulus is indicated by the bar. Maximal irradiance, $3.78 \mathrm{~W} / \mathrm{m}^{2}$.

dimensional reconstruction from continuous series of thin sections of an unstained NFB amacrine cell is presently in progress and will be presented elsewhere on completion.

The cytoplasm of NFB amacrine cells had a distinctive organization (Figs. 11-15): The lobular appendages were packed with synaptic vesicles, small vacuoles, mitochondria, tubular profiles of the endoplasmic reticulum, and multivesicular bodies. On the other hand, the terminal dendritic branches in the vitreal region of the IPL had few vesicles and mitochondria but contained vacuoles, multivesicular bodies, and profiles of the endoplasmic reticulum.

NFB amacrine cells established specialized contacts in seven different locations. In the scleral region of the IPL, they received synaptic input from two sources: (1) The dendrites that carry the lobular appendages were postsynaptic at dyad synaptic junctions to endings whose presynaptic active zone was characterized by a ribbon surrounded by a halo of vesicles. These endings presumably belong to cone bipolar cells, for rod bipolar endings are strictly confined to the most vitreal region of the IPL. The parent neuron of the other postsynaptic member of the dyad was not identified. (2) The vitreal aspect of the perikaryon of NFB amacrine cells, their primary dendrite, and the lobular appendages were postsynaptic at conventional synaptic junctions to processes that contained small agranular vesicles and, 
Dark Adapted

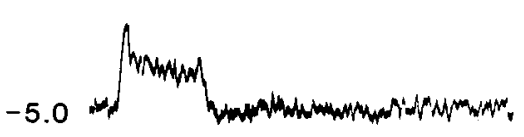

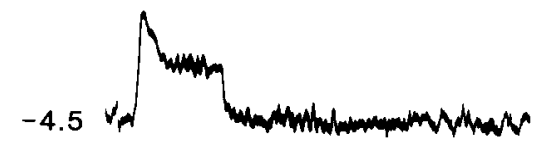

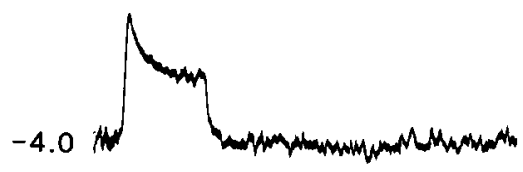

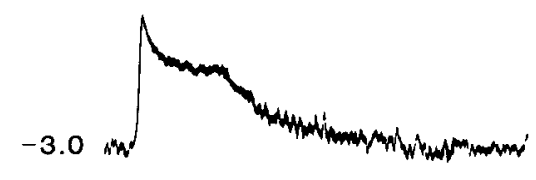

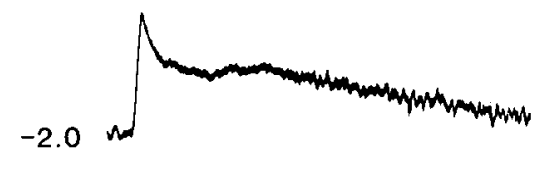

Light Adapted

Background -5.0
Light Adapted

Background -4.0

\section{-5.0 Antrim /}
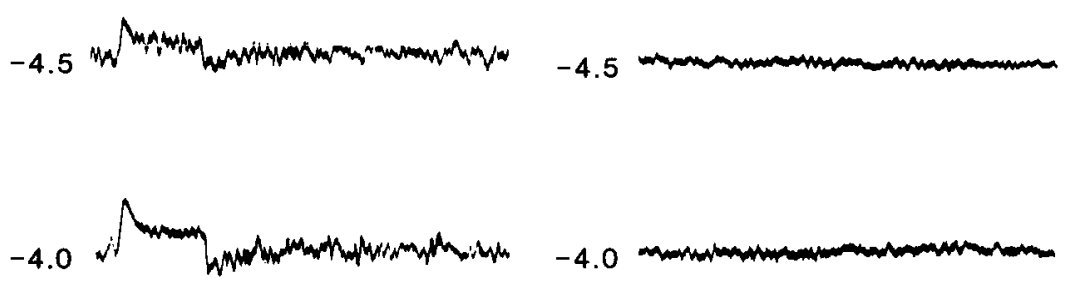

$-4.0$

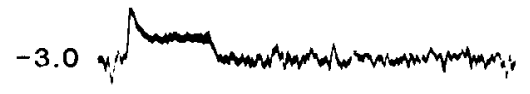

$-3.0$
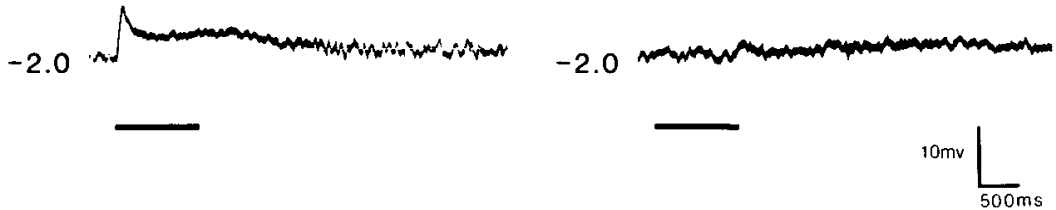

Figure 8. Effects of dark and light adaptation on the response of the rod bipolar of Figs. 4-7. With a background light of -5.0 log units, threshold increased from -6.0 to -4.5 . Saturation was reached at -4.0 , but the amplitude of the response was decreased with respect to the dark-adapted state. The depolarizing aftereffect is clearly visible at a flash intensity of -2.0 . When adapted with a saturating intensity $(-4.0)$, the cell failed to respond to flashes of any brightness. The presentation of the stimulus is indicated by the bar. Maximal irradiance, $3.78 \mathrm{~W} / \mathrm{m}^{2}$.
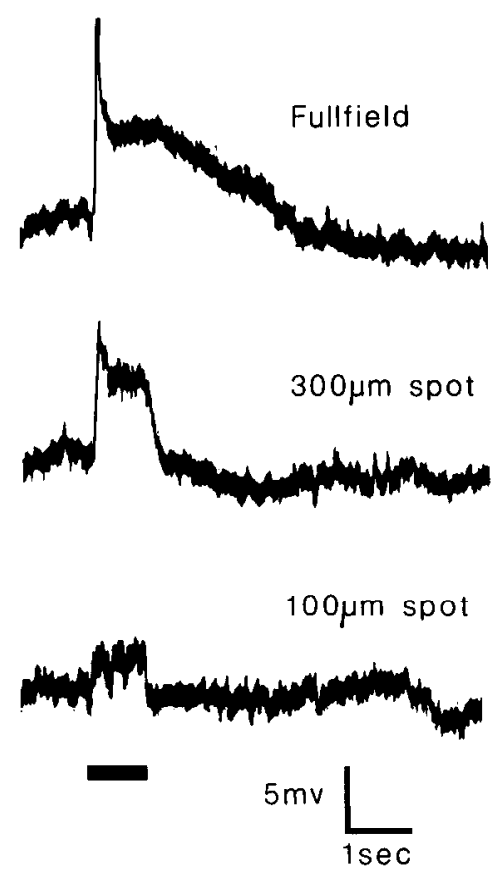

Figure 9. Responses of a rod bipolar cell to stimuli of different sizes; the intensity was kept constant at $-3.0 \mathrm{log}$ units. With a $300 \mu \mathrm{m}$ stimulus, the amplitude of the response decreased and the on-transient became less prominent. With a $100 \mu \mathrm{m}$ spot, the response was transformed into a low-amplitude, monophasic potential. The presentation of the stimulus is indicated by the bar. Maximal irradiance, $3.78 \mathrm{~W} / \mathrm{m}^{2}$. occasionally, a large dense-core vesicle. These processes presumably belong to one other type, or types, of amacrine cells; some or all of them may arise from the dopaminergic neurons described in the rabbit by several workers (Dowling and Ehinger, 1978; Holmgren-Taylor, 1982). To date, we have observed a single synaptic output of NFB amacrine cells in the scleral region of the IPL: (3) The lobular appendages contacted large processes, which could be identified as ganglion cell dendrites because of their contents of microtubules, profiles of the smooth endoplasmic reticulum, and occasional ribosomes (Fig. 11). At the site of apposition, the surface of the lobular appendage was indented and the intercellular space was enlarged; furthermore, one had the impression that synaptic vesicles were packed more tightly near the plasma membrane of the lobular appendage. This point, however, needs confirmation from thin sections of an unstained, serially reconstructed NFB amacrine cell.

In the vitreal region of the IPL, the dendrites of NFB amacrine cells received synaptic input from three different sources and established gap junctions with neighboring processes: (4) They were postsynaptic at dyad synaptic junctions to rod bipolar endings, which were easily identified on account of their large size, position at the extreme vitreal boundary of the IPL, and presence of a ribbon, surrounded by a halo of vesicles, at the presynaptic active zone (Fig. 13). Only one of the two members of the dyad belonged to an NFB amacrine cell and had a small diameter; as previously mentioned, the other member had a pale matrix, contained numerous synaptic vesicles, and often returned a reciprocal synapse onto the bipolar ending. Most likely, it belongs to another amacrine cell, perhaps the equivalent in the rabbit of cat's amacrine A17, which is connected 


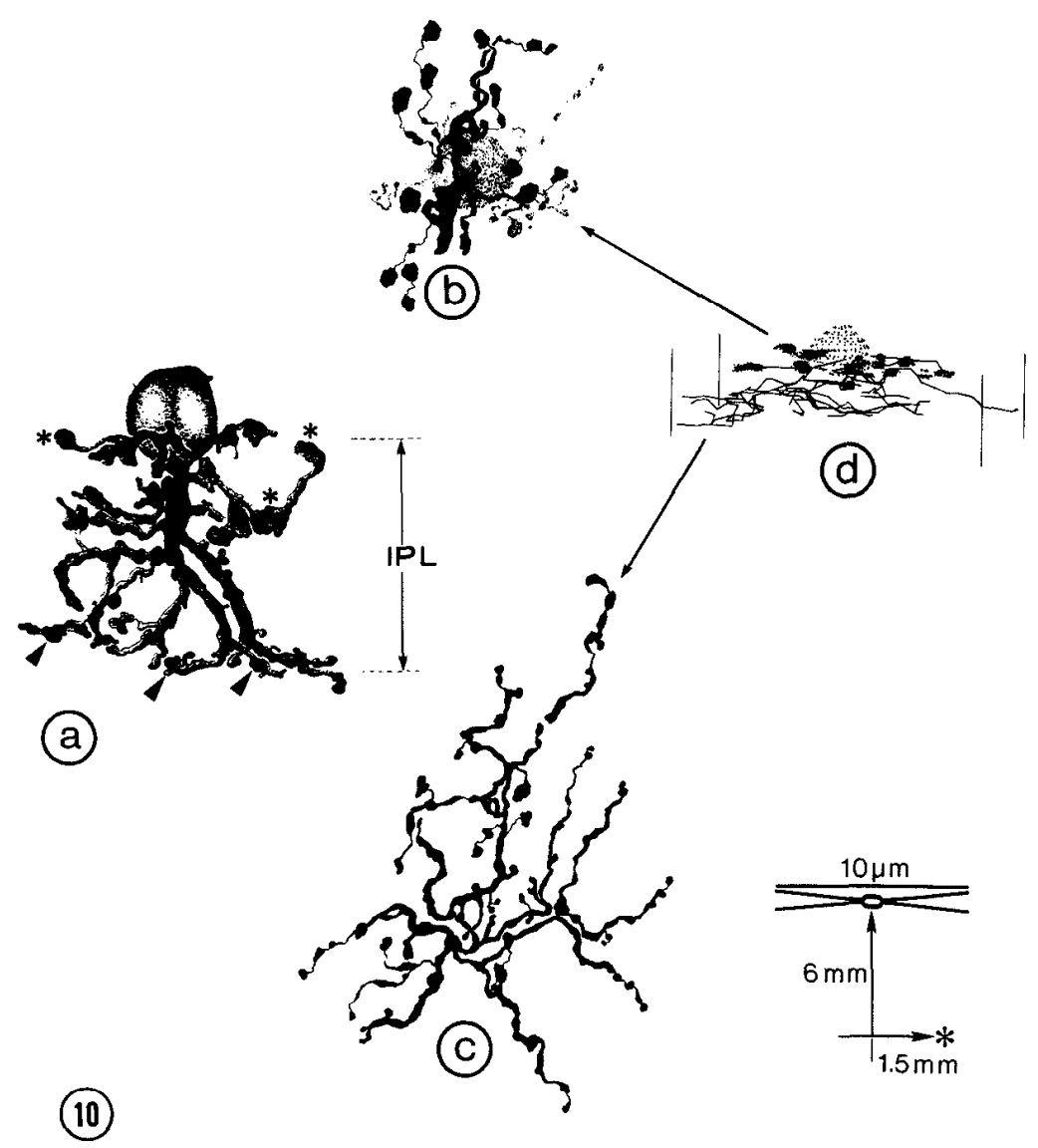

Figure 10, a, NFB amacrine cell impregnated with the Golgi technique was drawn with the camera lucida from a radial section of the retina. In the scleral region of the IPL, tortuous, collateral branches arise from the cell body and primary dendrite; they carry large, irregular endings or lobular appendages (asterisks). In the vitreal region of the IPL, the primary dendrite gives rise to a conical tuft of secondary branches that spread tangentially at the boundary between IPI and ganglion cell layer; these carry swellings, either terminal or en passant (arrowheads) and occasional spines. $b$ and $c$, Two optical sections through an HRP-stained, NFB amacrine cell were drawn at the camera lucida from a flat-mounted retina. In $b$ is illustrated the en face view of the scleral portion of the cell's dendritic tree with its distinctive lobular appendages; in $c$ is the orthogonal projection of the vitreal tuft of secondary dendrites. The cell was subsequently reconstructed by computer graphics and rotated about $80^{\circ}$ to observe its "profile" view $(d)$ : It appears distinctly bistratified within the IPL, whose thickness is indicated by the vertical bars. The diagram at lower-right corner illustrates the position of the HRP-stained cell with respect to the optic nerve head and medullary rays. Magnification, $\times 2700$.

to rod bipolar endings (Kolb and Nelson, 1981). (5) In the middle of the IPL, a process of an NFB amacrine cell was postsynaptic at a dyad synaptic junction to a small, ribboncontaining ending (Fig. 12). We could not decide whether the parent neuron of this ending was a rod or, more likely, a cone bipolar cell. (6) Throughout the vitreal region of the IPL, the processes of NFB amacrine cells were postsynaptic at conventional synaptic junctions to endings containing small agranular vesicles, in places associatcd with a large, densc-corc vesiclc: They presumably belong to other types of amacrine cells. (7) Finally, NFB amacrine cell dendrites were connected by small gap junctions to processes located in the vitreal third of the IPL. Some of these processes contained a similar, sparse complement of cytoplasmic organelles as the HRP-stained, NFB amacrine cell process, namely, a few vesicles, vacuoles, multivesicular bodies, and elongate profiles of the endoplasmic reticulum (Fig. 14 ); other processes were filled with synaptic vesicles. In places, $Y$-shaped gap junctions were found connecting the tips of three converging processes; one was filled with HRP and one of the other two contained numerous synaptic vesicles (Fig. 15). Thus, it seems that NFB amacrine cells are connected by gap junctions to one another as well as to vesicle-rich endings of unknown origin.

\section{Electrophysiology}

The intracellular response of NFB amacrine cells was a transient-sustained, graded depolarization to step changes in the intensity of diffuse, white light stimulation; in addition, the cells generated a prominent, spontaneous noise in the dark (Fig. 16). The threshold of the response was the same as that of depolarizing rod bipolars: A $-6.0-\log$ unit stimulus elicited a slow, lowamplitude, monophasic depolarization. A 1-log unit increase in stimulus intensity transformed the response into a triphasic potential, which was characterized by a transient depolarization at initiation of illumination, followed by repolarization to a lowamplitude, sustained plateau phase, and finally, by a transient hyperpolarization at off. With a stimulus of rod-saturating intensity $(-4.0)$, the on-transient became very prominent, and it was followed by a small, negative notch that preceded the sustained component of the response; in addition, the off-hyperpolarization gained in amplitude and sharpness, but repolarized more slowly to dark level. A flash 1 log unit above rod saturation $(-3.0)$ caused an attenuation of the hyperpolarizing off-transient; with brighter stimuli ( -2.0 to 0.0$)$, this transient disappeared altogether and a secondary depolarization developed, which was equal in amplitude to the sustained phase of the primary response and returned slowly to dark level over a time of several seconds. This secondary depolarization had the same threshold, shape, and duration as the afterpotentials generated by high-intensity stimuli in rod bipolar cells and axon terminals of axon-bearing horizontal cells; all may result from and mirror the time course of rod saturation (Dacheux and Miller, 1981).

Since the EM analysis had shown that NFB amacrine cells were postsynaptic to both rod and cone bipolars, as well as to other types of amacrine cells, their responses under dark and light adaptation were compared in an attempt to unravel rod and cone contributions to the waveform of their response. An adapting intensity just below rod saturation $(-4.5)$ was chosen, so that rods were severely affected, but cones were still very sensitive. In Figure 17, the responses elicited by flashes superimposed on the adapting light (right column) are compared with those recorded from the same cell in conditions of dark adaptation (left column). In the light-adapted retina, the transientsustained depolarization was reduced to about $25 \%$ of its am- 

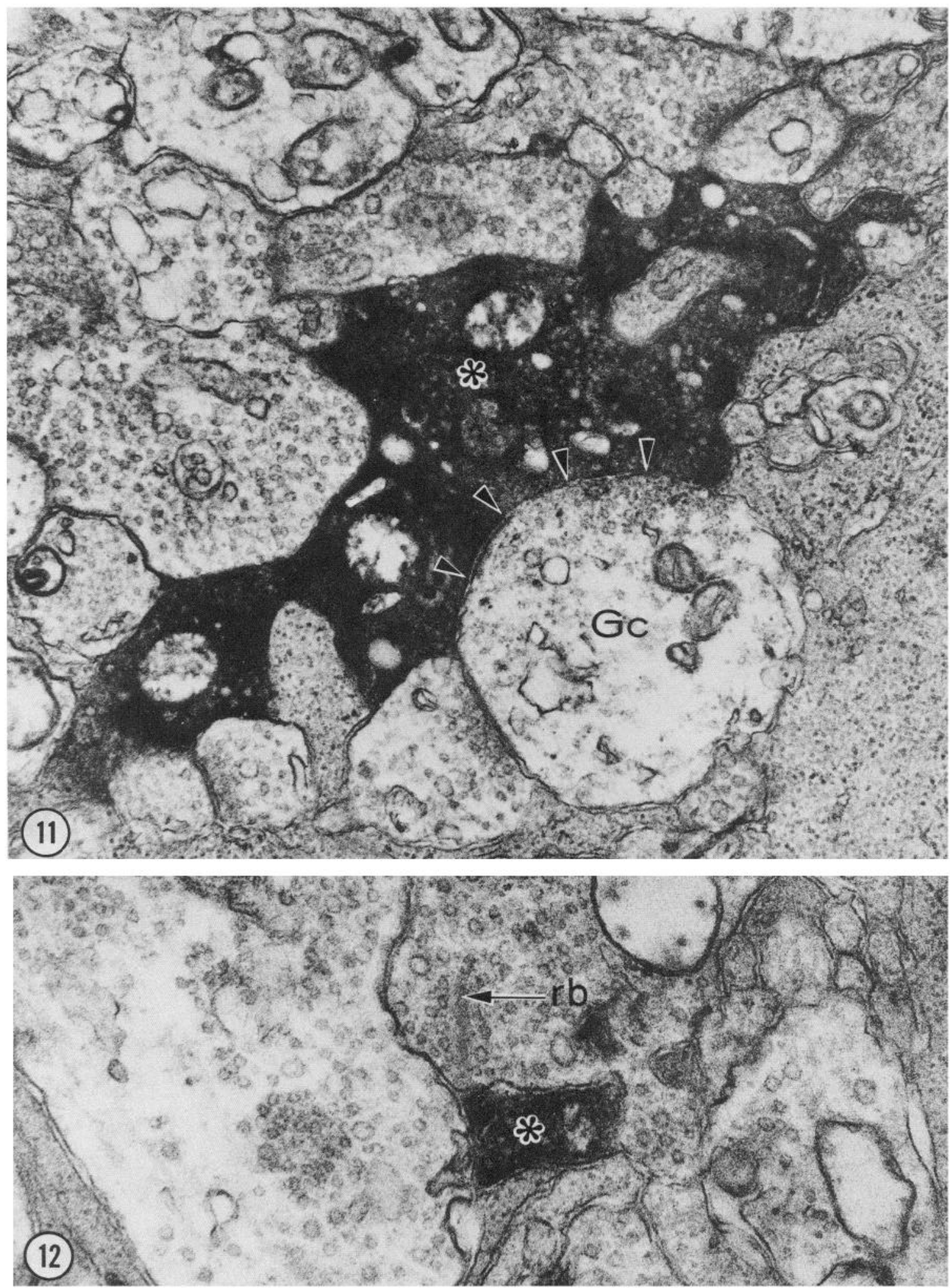

Figures 11 and 12: Figure 11, Lobular appendage of the HRP-stained NFB amacrine cell of Fig. 10, $b$ and $c$ (asterisk), contains a rich complement of cytoplasmic organelles; these include mitochondria, a multivesicular body (just beneath the asterisk), vacuoles, tubular profiles of the endoplasmic reticulum, and numerous vesicles. The ending contacts a round, pale process $(G c)$, most likely a ganglion cell dendrite because it has large size and contains irregular profiles of the endoplasmic reticulum. At the site of apposition, synaptic vesicles within the cytoplasm of the lobular appendage seem to cluster near the plasma membrane (arrowheads). Magnification, $\times 33,000$. Figure 12, Dendrite of the same HRP-stained NFB amacrine cell (asterisk) is postsynaptic at a dyad synapse to a ribbon-containing ending, located approximately midway between scleral and vitreal borders of the IPL. $r b$, Synaptic ribbon. Magnification, $\times 39,500$. 

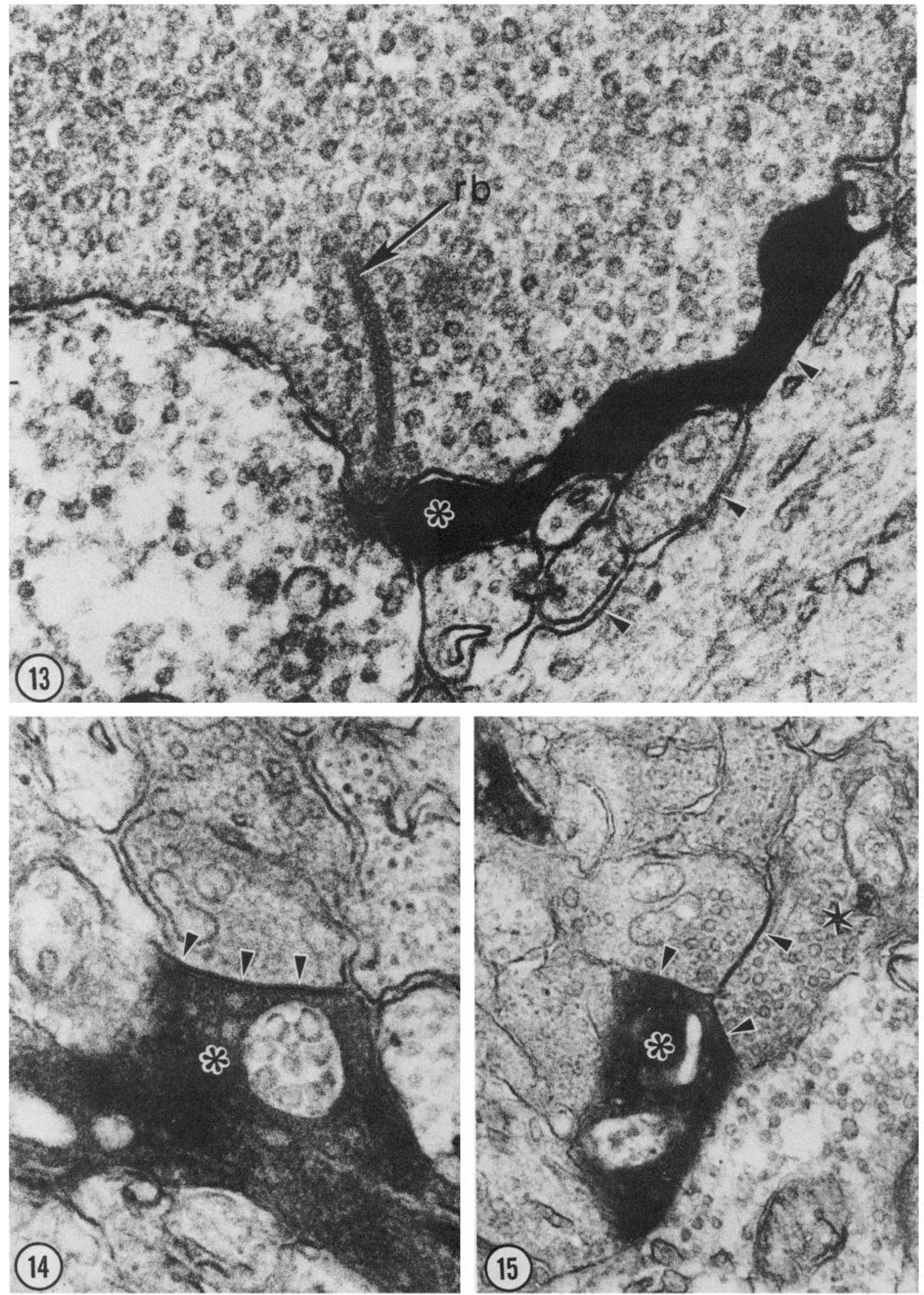

Figures 13, 14, and 15: Figure 13, NFB amacrine cell dendrite (asterisk) situated at the very boundary between IPL and ganglion cell layer (arrowheads) is postsynaptic at a dyad synapse to a ribbon-containing ending. This, in turn, belongs to a rod bipolar cell, because of its large size and position at the vitreal border of the IPL. $r b$, Synaptic ribbon. Magnification, $\times 87,000$. Figure 14, In the vitreal region of the IPL, a dendrite of the HRP-stained NFB amacrine cell (asterisk) is connected by a gap junction (arrowheads) to an adjoining process, which contains a few vesicles and irregular vacuoles. Note the multivesicular body in the cytoplasm of the NFB amacrine cell dendrite. Magnification, $\times 115,000$. Figure 15, Three processes in the vitreal region of the IPL are connected by gap junctions arranged in a trigonal pattern (arrowheads). One process belongs to the HRP-stained, NFB amacrine cell (asterisk); of the two other processes, one is very rich in synaptic vesicles (star). Magnification, $\times 49,000$. 


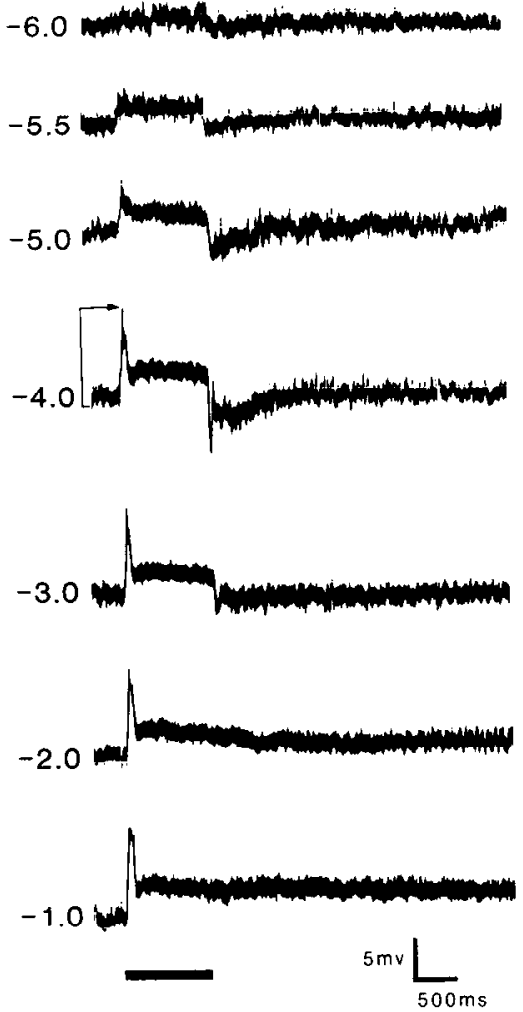

Figure 16. Light responses of the NFB amacrine cell illustrated in Fig. $10, b$ and $c$. The cell began to respond with the same flash intensity $(-6.0)$ that evoked a threshold depolarization in rod bipolar cells. At a saturating intensity $(-4.0)$, the response was characterized by a transient depolarization at on, followed by a repolarization to a low-amplitude plateau phase, and finally by a transient hyperpolarization at off. With a -3.0 stimulus, the off-transient became attenuated; with brighter flashes $(-2.0$ and -1.0$)$, it disappeared. At these high intensities, the response acquired a depolarizing aftereffect, which was equal in amplitude to the sustained phase of the primary response and declined to dark level with a time course of several seconds. Note the prominent, spontaneous noise generated by the cell in the dark. The amplitude measurements reported in the text were made at the point indicated by the arrow. The presentation of the stimulus is indicated by the bar. Maximal irradiance, $3.78 \mathrm{~W} / \mathrm{m}^{2}$.

plitude in the dark-adapted state and the depolarizing aftereffect became very small; this strengthencd the idea that the depolarizing components of the NFB amacrine cell response are largely determined by rod input. The transient off-hyperpolarization was not affected by light adaptation; this finding suggests that it is cone dependent. As in dark adaptation, it disappeared with bright stimuli $(-2.0)$.

Examination of the NFB amacrine cell recordings at a high sweep speed (Fig. 18) revealed complex details of the response waveform, which were filtered out by the limited frequency resolution of the penwriter. A consistent feature of the responses was three to five fast, oscillatory potentials, riding at a frequency of $200 \mathrm{~Hz}$ on the peak of the initial, transient event. Although at low sweep speed, the response seemed to saturate with flashes of a -4.0 intensity, at high sweep speed, the amplitude of the initial depolarization increased throughout the range of the highintensity flashes; this increase was totally accounted for by the increment in amplitude of the oscillatory potentials.

When the retina was adapted with a weak, continuous, background illumination that did not abolish the cell response ( -5.5$)$, the oscillatory potentials disappeared and the initial transient event was transformed into a smooth depolarization (Fig. 19). The oscillatory potentials began to reappear $10 \mathrm{sec}$ after removal of the background light. This finding suggests that the initial, transient event in the NFB amacrine cell response consists of two components: A slower, smooth depolarization, which saturated with a stimulus intensity of -4.0 to $-3.0 \mathrm{log}$ units, and fast oscillatory potentials. These did not saturate in the darkadapted retina but were abolished by a background illumination whose intensity was below rod saturation.

The spatial properties of the receptive field of NFB amacrine cells were tested by varying the diameter of the illuminating spot centered over the electrode, while the intensity of the flash was kept constant at 1 log unit above saturation $(-3.0)$. Decreasing the stimulus diameter to $100 \mu \mathrm{m}$ had little effect on the response (Fig. 20); however, when a $50 \mu \mathrm{m}$ spot was presented, a $50 \%$ attenuation in the amplitude of the triphasic potential was observed, although its waveform remained constant. Thus, the diameter of the cell's receptive field measured between 50 and $100 \mu \mathrm{m}$. When the spot was displaced 10 to 20 $\mu \mathrm{m}$ toward the periphery of the receptive field, no effect was observed; beyond $20 \mu \mathrm{m}$, however, a pure hyperpolarization was elicited, which abruptly appeared at stimulus initiation, slowly decayed throughout the duration of the stimulus, and repolarized to dark level at off. These findings indicate that NFB amacrine cells possess an antagonistic center-surround organization of their receptive field. It is surprising that the response still retained an on-transient on small spot stimulation; however, we cannot rule out the possibility that the diameter of the spot was still too large to evoke a pure center response.

\section{Discussion}

The present study reports that two depolarizing neurons, a bipolar and an amacrine cell, sequentially transfer rod signals to ganglion cells in the rabbit retina (Fig. 21). Rod bipolars receive
Figure 17. When the retina was adapted with diffuse light of an intensity just below rod saturation $(-4.5)$, the transient-sustained depolarization of the NFB amacrine cell was markedly reduced in amplitude and the aftereffect nearly disappeared. In both dark- and light-adapted conditions, the transient off-hyperpolarization was elicited by stimuli of intermediate intensity $(-4.0$ and -3.0$)$ and disappeared with brighter flashes $(-2.0)$. The presentation of the stimulus is indicated by the bar. Maximal irradiance, $3.78 \mathrm{~W} / \mathrm{m}^{2}$.
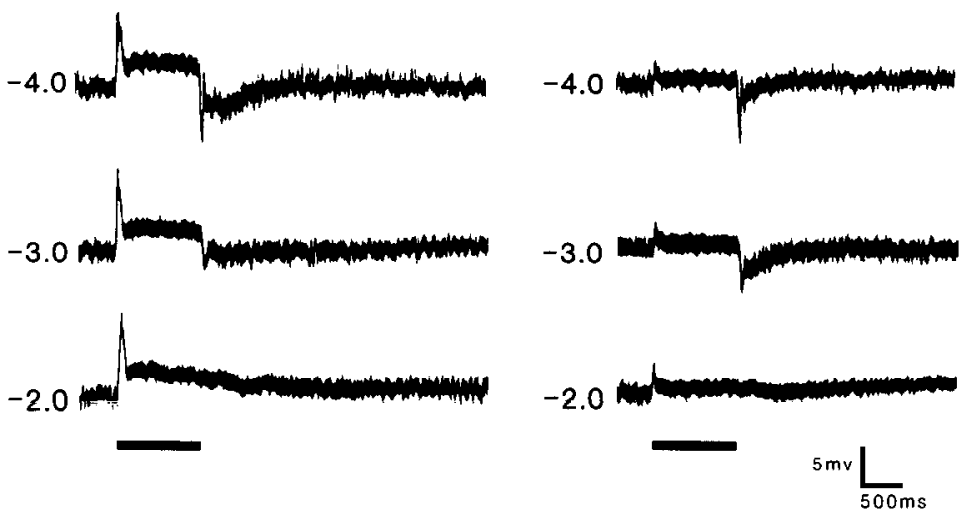


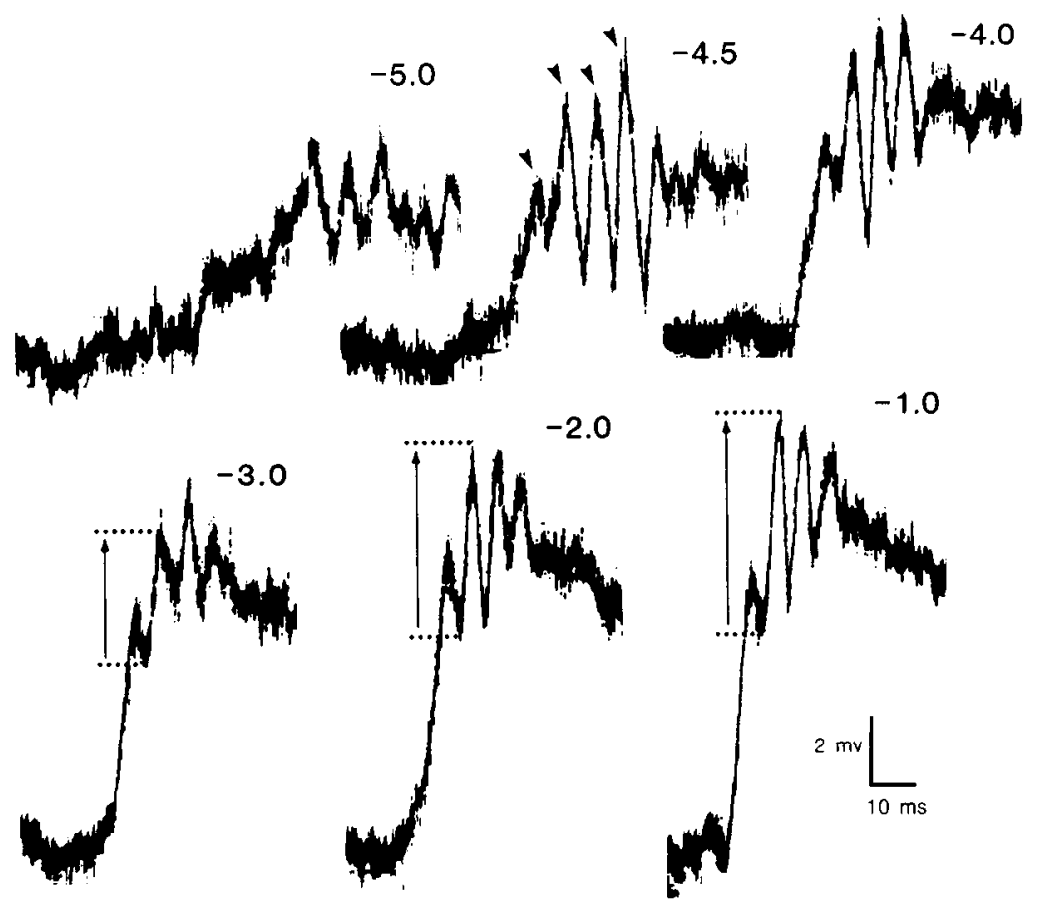

Figure 18. NFB amacrine cell responses are illustrated here at a high sweep speed; only the initial $60 \mathrm{msec}$ are shown. Four, fast oscillatory potentials (arrowheads) ride on the peak of the initial transient event; their amplitude (arrows) increased throughout the range of stimulus intensities. Initiation of the $1 \mathrm{sec}$ flash coincides with the beginning of the trace. Maximal irradiance, $3.78 \mathrm{~W} / \mathrm{m}^{2}$.

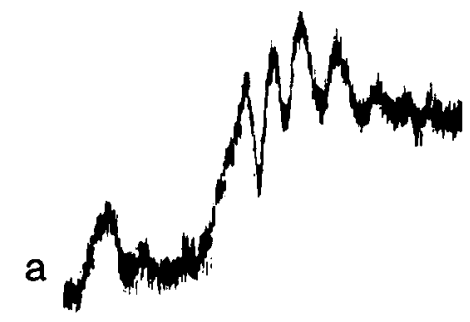

synaptic input from rod cells in the OPL, where their dendrites end as central elements of the invaginating synapse of rod spherules. Their main synaptic output in the IPL is onto NFB amacrine cells and at least one other type of amacrine cell. The light response of rod bipolars, or a variety of them, is a transientsustained depolarization, characterized by the same low threshold as the axonal endings of axon-bearing horizontal cells, which
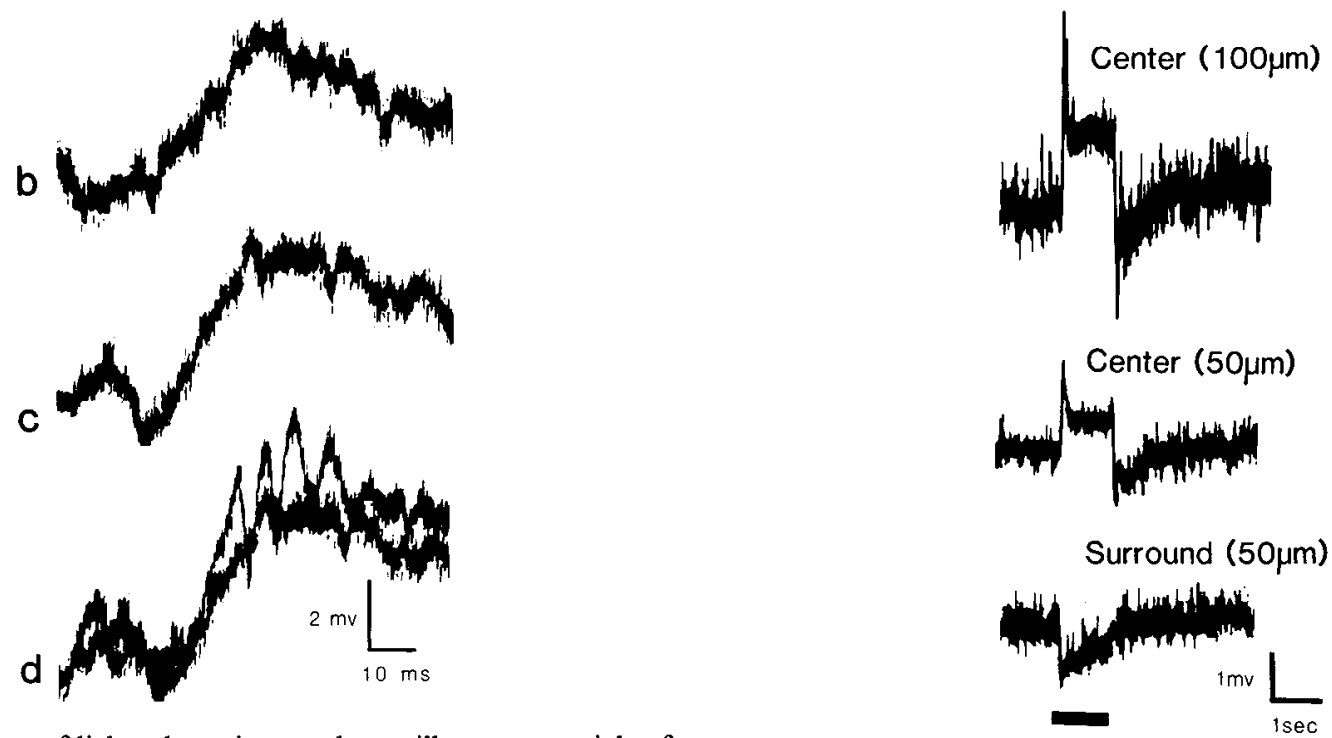

Figure 19. Effects of light adaptation on the oscillatory potentials of an NFB amacrine cell. $a$, Cell response to a $\mathbf{- 4 . 0}$ flash in conditions of dark adaptation: Four oscillatory potentials occurred at the onset of the response. $b, \mathbf{A}-4.0$ test flash was superimposed on a constant, -5.5 log-unit, background illumination: The oscillatory potentials were abolished and the on-transient was transformed into a slower, smooth depolarization. c; A -4.0 hash was delivered to the retina $10 \mathrm{sec}$ after removing the background light: The oscillatory potentials began to reappear. $d$, Responses shown in $a$ and $c$ are superimposed to illustrate that the on-transient of NFB amacrine cells consists of oscillatory potentials riding on a slower, depolarizing wave. Maximal irradiance, $3.78 \mathrm{~W} / \mathrm{m}^{2}$.

Figure 20. Response waveform of the NFB amacrine cell was the same when the retina was stimulated with diffuse light or a $100 \mu \mathrm{m}$ spot centered over the electrode. With a $50 \mu \mathrm{m}$ spot, the amplitude of the triphasic potential was reduced, but its waveform remained the same. When the $50 \mu \mathrm{m}$ spot was displaced $50 \mu \mathrm{m}$ away from the electrode tip, the response changed into a hyperpolarization. Current was injected through the electrode in the time interval elapsing between top and middle response: This explains the reduction in electrode noise between the two traces. The presentation of the stimulus is indicated by the bar. Flash intensity, $-3.0 \log$ units. Maximal irradiance, $3.78 \mathrm{~W} / \mathrm{m}^{2}$. 


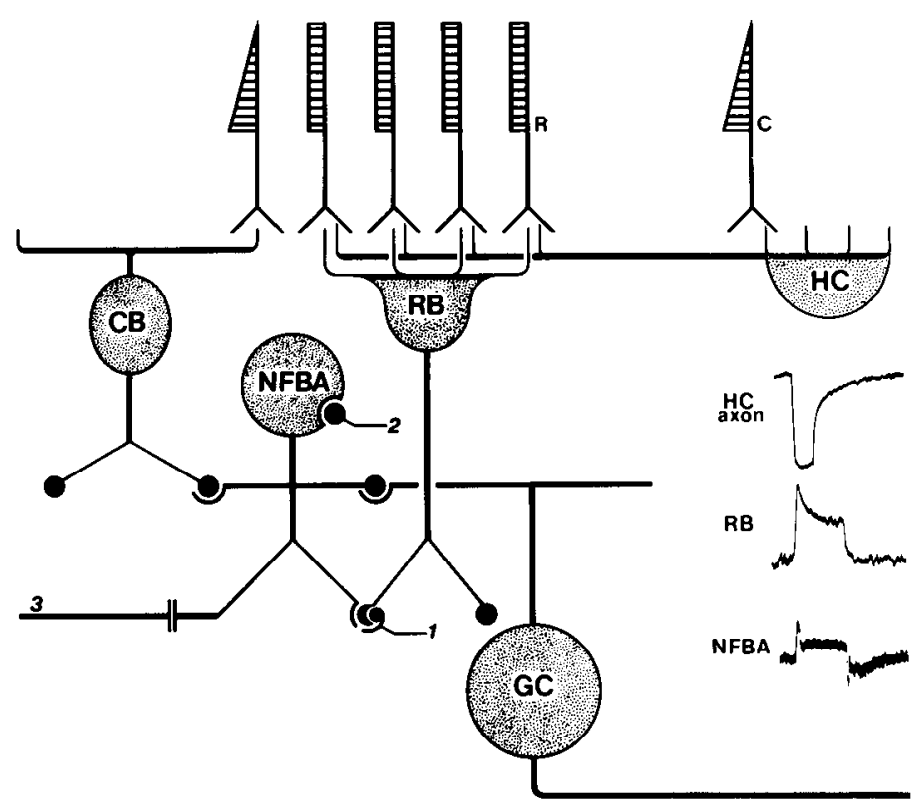

Figure 21. Diagram of the neural interactions in the rod pathway of the rabbit retina described in this paper. Rod cells $(R)$ synapse with the axonal endings of axon-bearing horizontal cells $(H C)$ and the dendrites of rod bipolar cells $(R B)$. Rod bipolars are in turn presynaptic to narrowfield, bistratified amacrine cells $(N F B A)$ and to a second type of amacrine cell $(1)$, which returns a feedback synapse onto the bipolar endings. The narrow-field, bistratified amacrine cell also receives synaptic input from cone bipolars $(C B)$ and one or more additional varieties of amacrine cells (2). In turn, it is presynaptic to the dendrites of ganglion cells $(G C)$ in the scleral region of the IPL and makes gap junctions with other cell processes (3) in the vitreal region of the IPL. The axon terminals of axon-bearing horizontal cells give a hyperpolarizing light response, whereas rod bipolars and narrow-field, bistratified amacrine cells are both depolarizing. $C$, Cone cell.

are connected to rods (unpublished observations). It becomes rapidly saturated with increasing stimulus intensity; furthermore, with bright illumination, it develops at off a secondary depolarization similar in time course to the rod aftereffect of horizontal cells (Dacheux and Raviola, 1982; Nelson, 1977; Nelson et al., 1976; Steinberg, 1969), although opposite in polarity. When the retina is adapted with a background illumination of saturating intensity, the cells fail to respond. This intensity is the same that abolishes the rod aftereffect in axonless horizontal cells, which are postsynaptic to cones, without suppressing their primary response (Dacheux and Raviola, 1982). All these findings, taken together, strongly support the idea that the light response of rod bipolars is dominated by rods and that their secondary depolarization is indeed homologous to the rod aftereffect recorded from all types of horizontal cells.

It is surprising that rod bipolars receive negligible cone input, first, because one of these bipolars was postsynaptic to two cones; second, because rods and cones in the rabbit are connected by gap junctions and are probably electrically coupled (Raviola and Gilula, 1973, 1975). Rod signals do in fact trickle into the response of axonless horizontal cells, which are exclusively connectcd to concs (Dachcux and Raviola, 1982). There are simple explanations for this unexpected finding. On the one hand, synaptic input from two cones in a cell which contacts about 100 rods may not be detected on recording from the cell body. On the other hand, the cone signals that spread to rod spherules through the interreceptor junctions may be too small to influence the bipolar cell response: In the rabbit, cones are much fewer than rods; each cone pedicle receives the influence of numerous rods, but very few cones converge on each rod. Thus, in contrast with the axon terminal of axon-bearing hor-
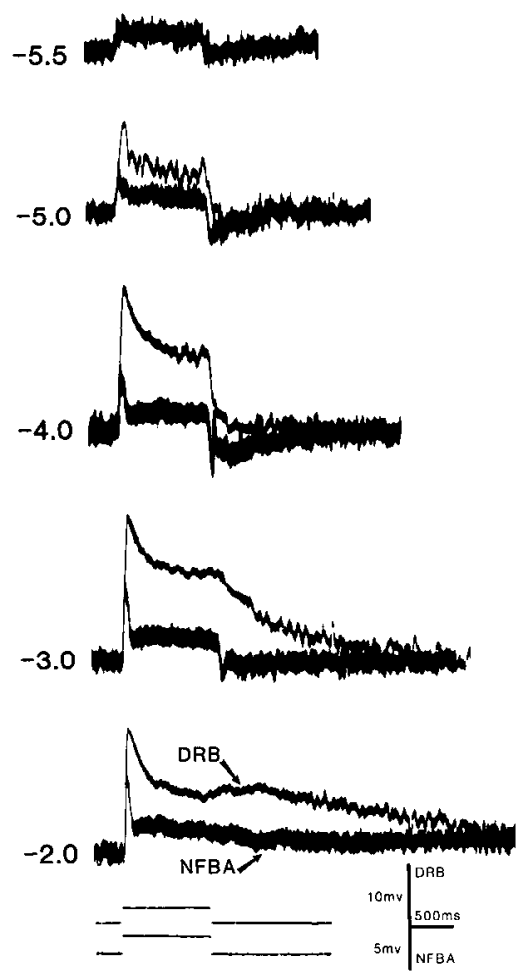

Figure 22. Light responses of a depolarizing rod bipolar $(D R B)$ and an NFB amacrine cell (NFBA) are superimposed to illustrate their similarities; in both instances the retina was dark-adapted. The presentation of the stimulus is indicated below. Maximal irradiance, $3.78 \mathrm{~W} / \mathrm{m}^{2}$.

izontal cells, the cones encompassed by the dendritic tree of a rod bipolar may be too few to influence the bipolar response. Unfortunately, a chromatic analysis of bipolar cell responses in the rabbit is very difficult, because in this species red cones are absent, blue cones are few, and green cones have a spectral sensitivity very close to rods (Caldwell and Daw, 1978; De Monasterio, 1978; Nuboer and Moed, 1983; Nuboer et al., 1983). The presence of cone synapses onto rod bipolars is in contrast to existing observations in other mammalian species (Boycott and Kolb, 1973; Kolb, 1970), with the single exception of the gray squirrel retina, which possesses mixed bipolars (West, 1978). Since these connections do not seem functionally significant, they may represent an anomaly that reflects the developmental history of rod bipolars.

Although we could not hold the impaled rod bipolars long enough to elicit a pure surround response, we suspect that this cell type has a center-surround organization of its receptive field, on the basis of the biphasic waveform of its response to diffuse stimuli as opposed to a monophasic, square depolarization to a small spot. Furthermore, previous studies in young rabbits showed that cells with similar response properties do possess a concentric type of receptive field (Dacheux and Miller, 1981).

NFB amacrine cells receive synaptic input from rod bipolars, cone bipolars, and other types of amacrine cells. Additional work is required to characterize their output, but they are probably presynaptic to ganglion cell dendrites with their lobular appendages. Furthermore, in the vitreal region of the IPL, they also communicate via gap junctions with other neurons, whose identity has not yet been established with certainty (Fig. 21).

Although we could not demonstrate directly that the NFB amacrine cell is postsynaptic to the depolarizing rod bipolar, indirect evidence strongly suggests that this hypothesis is correct: (1) Thresholds of the responses are nearly identical, and (2) both cells exhibit a depolarizing rod aftereffect at the termination of bright stimuli. Figure 22 illustrates the similarities 
in the responses of the two neurons. Thus, NFB amacrine cells are inserted in series along the rod pathway and mediate the transfer of scotopic signals from rod bipolars to ganglion cells. Four additional features, however, appear in the electrical activity of this amacrine cell type: (1) Fast, oscillatory potentials ride on the initial transient depolarization; (2) the decay of the transient event at stimulus initiation is faster than in depolarizing rod bipolars; (3) they respond to stimuli of intermediate light intensity with a transient hyperpolarization at off; and (4) they generate pronounced noise in the dark.

Analysis of the NFB amacrine cell response at high sweep speed revealed details of its waveform that escaped the attention of previous investigators. The initial, transient event seems to consist of fast, oscillatory potentials riding on a slower, smooth depolarization. Their significance is unknown; future work will clarify whether they represent $\mathrm{Na}^{+}$or $\mathrm{Ca}^{2+}$ spikes, either dendritic or somatic in origin. They have a striking resemblance with, and may be related to, the oscillatory potentials seen on the smooth envelope of the ERG b-wave (Algvere et al., 1972; Cobb and Morton, 1954); not only are their number and frequency the same, but they behave in a similar fashion with dark and light adaptation. The rod or cone origin of the oscillatory potentials remains undecided, for they do not saturate with highintensity illumination in the dark-adapted retina, but they are abolished by a weak background light. Possibly, they result from a complex, oscillatory feedback mechanism that operates along the rod pathway at the level of the IPL.

In contrast to the oscillatory potentials, the slow component of the initial transient of the response saturates at about the same intensity level as the rod bipolar response and may reflect the input from this neuron.

The mechanism for the sharpening of the on-transient in the amacrine, as compared with the bipolar response, is unclear; however, it is interesting to note that the cell depolarization caused by small spot stimulation retains the on-transient, instead of acquiring the square waveform that is typical of the center response of bipolar cells. Perhaps, the accentuation of the initial event in the NFB amacrine cell response results from an inhibitory feedback onto the bipolar ending by the other member of the dyad synapse. The rabbit may possess an amacrine cell type homologous to the A17 of the cat (Kolb and Nelson, 1981), whose only output consists of reciprocal synapses onto the rod bipolar endings: The indoleamine cell previously described in the rabbit (Ehinger, 1983; Ehinger and Holmgren, 1979) could be a likely candidate. Then, one can postulate that at the dyad synapse both postsynaptic processes are simultaneously activated by the bipolar ending; the indoleamine cell process, through its reciprocal synapse, accentuates in the bipolar ending the electrical events associated with stimulus onset and abruptly reduces its transmitter output. 'This would be mirrored in the NFB amacrine cell by a sharpening of the ontransient and its preservation with focal stimulation. Thus, the NFB amacrine cell is converted into a detector of stimulus initiation. The hyperpolarizing off-transient has the following properties: (1) It is cone-dependent and (2) it disappears with bright illumination, both in dark- and light-adapted retinas. The EM shows that NFB amacrine cells do indeed receive synaptic input from cone bipolar endings, which may be hyperpolarizing, since they are located in the scleral region of the IPL (Kolb and Nelson, 1983); in addition, they are also postsynaptic to amacrine cell processes. Then, the anatomical substrate for the offhyperpolarization may be represented either by the input from a hyperpolarizing cone bipolar or from a cone-driven amacrine cell. Perhaps, through these connections, a hyperpolarizing cone influence filters into the rod pathway to convey to ganglion cells a sharp signal of the termination of a mesopic stimulus. We do not know why the off-transient disappears with high stimulus intensities: Its absence may reflect an interaction with the de-
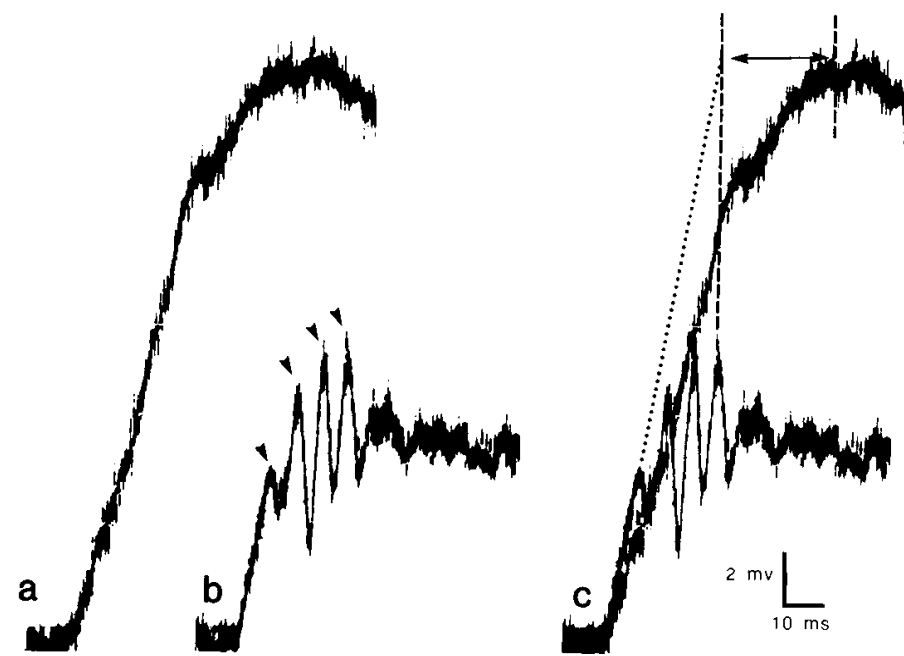

Figure 23. Leading edges of a rod bipolar $(a)$ and NFB amacrine cell (b) response are superimposed in $c$. The normalized response of the NFB amacrine cell (dotted line) peaks about $25 \mathrm{msec}$ before the bipolar response (arrow). The same time interval elapses between peak amplitude of the oscillatory potentials and that of the bipolar response (dashed lines). The arrowheads in $b$ indicate the oscillatory potentials in the NFB amacrine cell response. Dark-adapted retinas; intensity of the test flashes -4.0. Maximal irradiance, $3.78 \mathrm{~W} / \mathrm{m}^{2}$.

polarizing rod aftereffect. Alternatively, it represents an event that is expressed over a limited range of stimulus intensities and disappears in bright light as a result of an additional synaptic mechanism. The source of the noise of NFB amacrine cells remains obscure.

The anatomical basis for the antagonistic, center-surround organization of the receptive field of NFB amacrine cells is unknown: Either it is carried over from the rod bipolars presynaptic to them or is generated ex novo in the IPL by the input from other amacrine cells.

There are many similarities and crucial differences between the rod pathway in the rabbit and that described in the cat. In both species, the connectivity of rod bipolars and the synaptic inputs of NFB amacrine cells are basically the samc; furthermore, the response properties of NFB amacrine cells are remarkably alike. Yet, in the cat, rod bipolars appear to be hyperpolarizing; they do not seem to have antagonistic centersurround organization of their receptive field, and there is a striking mismatch between the sluggish onset of the bipolar response and the fast rise to peak amplitude of the amacrine cell on-transient. These observations led Nelson (1982) and Kolb and Nelson (1983) to postulate that the function of the axonal endings of horizontal cells is to mediate a facilitatory interaction among rods, that the ribbon synapse between rod bipolars and NFB amacrine cells is sign-inverting, and finally, that a function of NFB amacrine cells is to quicken the time course of the bipolar response. Furthermore, since rod bipolars in the cat lack a surround, one must conclude that the receptive field properties of NFB amacrine cells are generated in the IPL. In the rabbit, both rod bipolars and NFB amacrine cells are depolarizing; furthermore, there are indications that rod bipolars do have a surround. As a result of the presence of the oscillatory potentials, a comparison between the rise times of the responses in the rod bipolar and NFB amacrine cell is very difficult (Fig. 23): If we take as the slope of the amacrine cell response that of the leading edge of the on-transient, then peak amplitude is reached by the bipolar about $25 \mathrm{msec}$ after the amacrine cell; the delay is only $5 \mathrm{msec}$ at half peak amplitude. A similar time interval elapses between peak amplitude of the oscillatory potentials and that of the bipolar response. Thus, in 
the rabbit the depolarizing rod bipolar is faster than its hyperpolarizing counterpart in the cat. Considering, however, the complexity of the NFB amacrine cell response and the lack of information on the synaptic mcchanisms that detcrmine its waveform, these comparisons of rise times are not very useful; in addition, they can be properly addressed only when recordings from the ganglion cells that receive their input from the NFB amacrine cell have been obtained.

In conclusion, the neural interactions along the rod pathway in the rabbit appear to be very straightforward: The surround response that we detect in NFB amacrine cells may be generated in the OPL by the axonal endings of axon-bearing horizontal cells; the ribbon synapse between rod bipolars and NFB amacrine cells is sign-conserving; and there seems to be little need for NFB amacrine cells to quicken the bipolar response.

We do not know whether all rabbit rod bipolars depolarize with stimulation. It seems odd that rod bipolars should depolarize in the rabbit and hyperpolarize in the cat (Kolb and Nelson 1983; Nelson and Kolb, 1983; Nelson et al., 1976): It is more likely that both retinas possess two physiological varieties of rod bipolars and that the apparent interspecies discrepancy results from a sampling bias by the electrodes.

According to the sublamination model of the IPL (Famiglietti and Kolb, 1976), on-and off-ganglion cells spread with their dendrites in different sublaminas of the IPL (Nelson et al., 1978). It was originally thought that the axonal endings of on- and offcone bipolars were also anatomically segregated within the appropriate sublaminas, but more recently, an off-cone bipolar that terminates in the on-sublamina of the IPI, has been stained (Nelson and Kolb, 1983). Another remarkable exception is represented by the hyperpolarizing rod bipolar of the cat, whose endings are located at the vitreal boundary of the on-sublamina. However, this bipolar rarely synapses onto ganglion cell dendrites and uses NFB amacrine cells to gain access to the correct tier of the IPL. In the rabbit, the endings of the depolarizing rod bipolars are located in the appropriate sublamina of the IPL; clearly, one of the functions of NFB amacrine cells is routing the rod bipolar input to the different functional varieties of ganglion cells. However, the complexity of the response waveform of this neuron and its multiple synaptic connections suggest additional pivotal functions in processing rod signals in the rabbit retina.

\section{References}

Algvere, P., L. Wachtmeester, and S. Westbeck (1972) On the oscillatory potentials of the human electroretinogram in light and dark adaptation. Acta Ophthalmol. 50: 737-760.

Boycott, B. B., and J. E. Dowling (1969) Organization of the primate retina: Light microscopy. Phil. Trans. R. Soc. Lond. [Biol.] 255. 109-184.

Boycott, B. B., and H. Kolb (1973) The connections between bipolar cells and photoreceptors in the retina of the domestic cat. J. Comp. Neurol. 148: 91-114.

Caldwell, J. H., and N. W. Daw (1978) New properties of rabbit retinal ganglion cells. J. Physiol. (Lond.) 276: 257-276.

Cajal, S. R. y (1892) La rétine des vertébrés. Cellule 9: 121-225.

Cobb, W. A., and H. B. Morton (1954) A new component of the human electroretinogram. J. Physiol. (Lond.) 123: 36P.

Dacheux, R. F. (1982) Connections of the small bipolar cells with photoreceptors in the turtle. An electron microscope study of Golgiimpregnated, gold-toned retinas. J. Comp. Neurol. 205: 55-62.

Dacheux, R. F., and R. F. Miller (1981) An intracellular electrophysiological study of the ontogeny of functional synapses in the rabbit retina. I. Receptors, horizontal and bipolar cells. J. Comp. Neurol. 198: 307-326.

Dacheux, R. F., and E. Raviola (1982) Horizontal cells in the retina of the rabbit. J. Neurosci. 2: 1486-1493.

De Monasterio, F. M. (1978) Spectral interactions in horizontal and ganglion cells of the isolated and arterially-perfused rabbit retina. Brain Res. 150: 239-258.
Dowling, J. E., and B. B. Boycott (1966) Organization of the primate retina: Electron microscopy. Proc. R. Soc. Lond. [Biol.] 166: 80111 .

Dowling, J. E., and B. Ehinger (1978) Synaptic organization of the dopaminergic neurons in the rabbit retina. J. Comp. Neurol. 180: 203-220.

Ehinger, B. (1983) Connections between retinal neurons with identified neurotransmitters. Vision Res. 23: 1281-1292.

Ehinger, B., and I. Holmgren (1979) Electron microscopy of the indoleamine-accumulating neurons in the retina of the rabbit. Cell Tissue Res. 197: 175-194.

Fairén, A., A. Peters, and J. Saldanha (1977) A new procedure for examining Golgi impregnated neurons by light and electron microscopy. J. Neurocytol. 6: 311-337.

Famiglietti, E. V., and H. Kolb (1975) A bistratified amacrine cell and synaptic circuitry in the inner plexiform layer of the retina. Brain Res. 84: 293-300.

Famiglietti, E. V., and H. Kolb (1976) Structural basis for on- and off-center responses in retinal ganglion cells. Science 194: 193-195.

Holmgren-Taylor, I. (1982) Ultrastructure and synapses of the $\left[{ }^{3} \mathrm{H}\right]$ dopamine-accumulating neurons in the retina of the rabbit. Exp. Eye Res. 35: 555-572.

Kaneko, A. (1970) Physiological and morphological identification of horizontal, bipolar and amacrine cells in goldfish retina. J. Physiol. (Lond.) 207: 623-633.

Kolb, H. (1970) Organization of the outer plexiform layer of the primate retina: Electron microscopy of Golgi-impregnated cells. Phil. Trans. R. Soc. Lond. [Biol.] 258: 261-283.

Kolb, H. (1974) The connections between horizontal cells and photoreceptors in the retina of the cat: Electron microscopy of Golgi preparations. J. Comp. Neurol. 155: 1-14.

Kolb, H. (1977) The organization of the outer plexiform layer in the retina of the cat: Electron microscopic observations. J. Neurocytol. 6: $131-153$

Kolb, H. (1979) The inner plexiform layer in the retina of the cat: Electron microscopic observations. J. Neurocytol. 8: 295-329.

Kolb, H., and R. Nelson (1981) Amacrine cells of the cat retina. Vision Res. 21: 1625-1633.

Kolb, H., and R. Nelson (1983) Rod pathway in the retina of the cat. Vision Res. 23: 301-312.

Missotten, L. (1965) The Ultrastructure of the Human Retina, Editions Arscia Uitgaven, Brussels.

Morest, D. K., and R. R. Morest (1966) Perfusion-fixation of the brain with chrome-osmium solutions for the rapid Golgi method. Am. J. Anat. 118: 811-832.

Nelson, R. (1977) Cat cones have rod input: A comparison of the response properties of cones and horizontal cell bodies in the retina of the cat. J. Comp. Neurol. 172: 109-136.

Nelson, R. (1982) AII amacrine cells quicken time course of rod signals in the cat retina. J. Neurophysiol. 47: 928-947.

Nelson, R., and H. Kolb (1983) Synaptic patterns and response properties of bipolar and ganglion cells in the cat retina. Vision Res. 23: 1183-1195.

Nelson, R., A. von Lutzow, H. Kolb, and P. Gouras (1975) Horizontal cells in cat retina with independent dendritic systems. Science 189 : 137-139.

Nelson, R., H. Kolb, E. V. Famiglietti, and P. Gouras (1976) Neural responses in the rod and cone systems of the cat retina: Intracellular records and procion stains. Invest. Ophthalmol. 15: 946-953.

Nelson, R., E. V. Famiglietti, and H. Kolb (1978) Intracellular staining reveals different levels of stratification for on-and off-center ganglion cells in cat retina. J. Neurophysiol. 41: 472-483.

Nuboer, J. F. W., and P. J. Moed (1983) Increment-threshold spectral sensitivity in the rabbit. J. Comp. Physiol. 151: 353-358.

Nuboer, J. F. W., W. M. van Nuys, and J. F. Wortel (1983) Cone systems in the rabbit retina revealed by ERG-null-detection. J. Comp. Physiol. 151: 347-352.

Polyak, S. L (1941) The Retina, University of Chicago Press, Chicago.

Raviola, E., and N. B. Gilula (1973) Gap junctions between photoreceptor cells in the vertebrate retina. Proc. Natl. Acad. Sci. USA 70: $1677-1681$.

Raviola, E., and N. B. Gilula (1975) Intramembrane organization of specialized contacts in the outer plexiform layer of the retina. A freezefracture study in monkeys and rabbits. J. Cell Biol. 65: 192-222.

Raviola, G., and E. Raviola (1967) Light and electron microscopic 
observations on the inner plexiform layer of the rabbit retina. Am. J. Anat. 120: 403-426.

Steinberg, R. H. (1969) The rod after-effect in S-potentials from the cat retina. Vision Res. 9: 1345-1355.

Werblin, F. S., and J. E. Dowling (1969) Organization of the retina of the mudpuppy, Necturus maculosus. II. Intracellular recordings. J. Neurophysiol. 32: 339-555.

West, R. W. (1978) Bipolar and horizontal cells of the gray squirrel retina: Golgi morphology and receptor connections. Vision Res. 18: 129-136. 